FROM THE THIRD GENEVA CONFERENCE ON PERSON-CENTERED MEDICINE: SPECIAL INITIATIVES FOR PERSON-CENTERED CARE

\title{
International Federation of Medical Students Association: Views on Person-centered Medicine
}

\author{
Remco Kruithof ${ }^{a}$ and Chijioke Chikere Kaduru MD ${ }^{b}$ \\ a Liaison Officer for Research and Medical Associations, International Federation of Medical Students \\ Association (2009-2010) and final year Medical Student University of Lausanne, Switzerland \\ b President, International Federation of Medical Students Association (2010-2011) and Medical Doctor, Ghana
}

\section{Keywords}

Holistic approach, medicine, medical education, students

\section{Correspondence Address}

Remco Kruithof, Liaison Officer for Research and Medical Associations c/o IFMSA General Secretariat, World Medical Association, B.P. 63, 01212 Ferney-Voltaire, Cedex, France. E-mail: remco.kruithof@gmail.com

Accepted for publication: 31 January 2011

\section{Introduction}

The IFMSA is a non-political and non-profit organization recognized as one of the oldest and largest student-run organizations in the world. IFMSA was established in 1951 to serve as a platform for unity, collaboration and peace amongst international medical students. IFMSA has since expanded to include more than 100 national member organizations, representing over 1.2 million medical students worldwide. The IFMSA is officially recognized by the United Nations, the World Health Organization and the World Medical Association as the voice for international medical students and is invited to many of their annual conferences. Amongst these conferences is the World Health Assembly organized by the WHO where the IFMSA represents the views of future physicians on international health concerns. The IFMSA's activities range from raising awareness on public health, human rights and reproductive health issues to involving students actively in medical curricula reforms and medical education. Our activities also encompass the largest international student exchange program, with more than 11,000 medical students given the opportunity to experience medicine and research as practiced in countries other than their own. Our activities are initiated by students either to supplement their education as future health care practitioners, or to try to fill in a gap in their health system in support of the health of the population. Medical Education is at the core of IFMSA and is at the center of all our activities, given the need to ensure a new generation of better educated and better equipped doctors.

\section{Moving towards a person-centered model of clinical care}

With the world becoming more and more of a global village, many diseases cross borders quite frequently and chronic diseases are present in every country. This is clearly evident in the increasing incidence of diabetes and lifestyle related conditions such as HIV infection in the developed and developing world. In many places, drugs can now be selected based on the genomic profile of the individual patient, enabling greater tolerance and efficiency. All these new tools and new technologies can greatly improve treatment. But there is no use in prescribing a drug if the person does not take it. To this extent it is important that medical professionals work towards the adherence of the patient to the treatment strategy. Many ways can be used to increase the patients' motivation towards adherence to their treatment, but most successful consider the person as a whole, taking in account not only his biology, but also his social, psychological and religious dimensions. Considering the patient as a whole person allows clinicians to help the patient to choose the most appropriate treatment, whether it is drug-based or physiotherapy, psychotherapy or part of other healing strategies. It is more the applicability of the treatment to the person that is now important, than the treatment in itself.

Different diseases require different elements and extents of the person-centered approach. For example, in psychiatry or in the treatment of drug-dependence, there is a great need for the person to engage with the healing 
process. This can only be achieved through the creation of a strong therapeutic alliance which needs from the medical side a good understanding of the person and his motivations. Over time, an understanding of the background of each person will help the clinician to adjust treatment to the needs expressed by the patient. Personcentered care is also an essential approach in primary care, where doctors have to face many patients with chronic diseases which can rarely be cured, only controlled. Within primary care, doctors are also confronted with the need to treat more minor and less serious conditions which do not necessarily have a well understood biological basis, but which require close attention, for example, back pain. Back pain is difficult to treat pharmacologically and is almost always the consequence of several factors needing a complete understanding of the person to relieve it.

During medical training, students need to study extensively in order to become a good doctor, mastering clinical and communication skills, practising critical thinking, understanding the relationship between health and society, appreciating the need for life-long learning, teaching, teamwork as well as theoretical knowledge [1]. It is therefore important not to include within training only the in-depth study of the biomedical sciences, but to include as well social science, medical ethics, humanities and theology in order to be able to apply a person-centered approach [2]. Students need these additional sources of knowledge to be able to understand cultural, religious and personal differences in the presentation of symptoms and the necessity of given treatment. The World Federation for Medical Education (WFME) encourages integrating in theoretical and practical teaching the different aspects mentioned above. As the importance of the different aspects change in different settings, it is important for all medical students to have their training not only in academic teaching hospitals, but also in other settings, like primary care, nursing homes, clinics and other relevant environments [3].

This makes it possible for medical students to understand the nature and extent of the limitations of the 'classical' medical model and to assess, for themselves, the powers of additional approaches. Here, person-centered clinical practice allows preventing, promoting, curing and rehabilitating to be enacted at the same time, making care considerably more efficient within health systems. The IFMSA believes this holistic approach to be a key principle of relevance to every health system and encourages every medical school to integrate it within their philosophy of medicine.

\section{References}

[1] European Medical Student Association and the IFMSA, European Core Curriculum-the Students' Perspective, 2006.

[2] Karle, H. (2010) World Federation for Medical Education perspectives on person-centered medicine. International Journal of Integrated Care, 10, 14-17.

[3] IFMSA, Multidisciplinary Approaches to Healthcare, 2010. 